\title{
LONDOÑO SULKIN, Carlos. 2012. People of Substance: An Ethnography of Morality in the Colombian Amazon. Toronto/ Buffalo/ London. University of Toronto Press. 240 p.
}

Laura Pérez Gil (UFPR)
Em um artigo publicado em 1996, "Images of Nature and Society in Amazonian Ethnology", Eduardo Viveiros de Castro identificava três estilos analíticos na produção recente da etnologia indígena das Terras Baixas da América do Sul. Dois desses estilos, os nomeados por ele como "economia simbólica da alteridade" e "economia moral da intimidade" têm protagonizado nos últimos anos uma controvérsia a respeito dos elementos que definem a sociabilidade desses grupos humanos. Em certos casos, "falcões" e "pombas", para usar os apelidos propostos por Anne Christine Taylor, têm adotado posicionamentos acirrados em referência às diferenças de suas abordagens; em outros, tem-se procurado fórmulas de consenso, reconhecendo-se que tanto a predação como a convivência e o amor são constitutivos dos processos sociais. $A$ etnografia de Carlos Londoño Sulkin, como ele mesmo aponta, se enquadra nessa ambiência teórica. Formado no seio do grupo que sustenta e desenvolve suas etnografias no marco da "economia moral da intimidade", Londoño Sulkin, entretanto, incorpora e se inspira também em teorias desenvolvidas pelos autores da "economia simbólica da alteridade" assumindo o que ele denomina "pacote amazónico" (: 24). Este inclui três princípios que permeiam boa parte da etnologia atual sobre as Terras Baixas da América do Sul: os corpos humanos são fabricados socialmente; isso ocorre no marco de um cosmo perspectivista; e, nesse processo de produção e reprodução corporal e social, a predação é condição sine qua non. A incorporação dessas ideias, que têm um papel importante no conjunto da obra no que se refere à análise das teorias nativas sobre moralidade, é provavelmente uma das principais diferenças - em termos teóricos, já que também existem outras de conteúdo - entre este livro e uma versão anterior em castelhano (Muinane. 2004. Un proyecto moral a perpetuidad. Editorial Universidad de Antioquia.).

O foco da etnografia que nos ocupa são as teorias sobre moralidade de la Gente de Centro, autodenominação referida ao conjunto de comunidades constituídas a partir dos remanescentes de diversos grupos da Amazônia colombiana, falantes de Uitoto, Bora, Miraña, Muinane, Andoke, Nonuya e Ocaina, cujas populações sofreram 
um grande abalo demográfico e sociológico pela expansão das frentes de colonização, especialmente durante o holocausto do boom da borracha. Trata-se, efetivamente, dos descendentes daqueles povos tristemente conhecidos por terem sido as vítimas de um dos episódios mais estarrecedores da história indígena recente: a escravidão, tortura e etnocídio ocorridos no Putumayo sob a responsabilidade da Companhia anglo-peruana Casa Arana.

Por moralidade o autor entende o conjunto de percepções, reações, entendimentos e asseverações de caráter avaliativo, relativas às subjetividades, às ações, às pessoas, às qualidades e às formas de vida, em termos de se são admiráveis, desprezíveis, não têm nada digno de nota ou qualquer outro aspecto referido a juízos de valor (:3). A moralidade não é, certamente, um tema novo na etnologia amazônica recente. Vários autores têm abordado a temática, que, como indicado acima, tornou-se o Leitmotiv de um dos "estilos" da etnologia contemporânea. Entretanto, ou ela constitui uma questão periférica que aparece ao se tratarem outros assuntos, sem constituir o foco da etnografia; ou ela é tomada como uma premissa teórica mais do que como um recorte etnográfico - estando, por vezes, aparentemente impregnada de uma visão rousseauniana; ou, inclusive, gerando a dúvida de até que ponto a descrição moral do Outro não é fruto de uma extensão analógica, por usar o termo cunhado por Roy Wagner. Diferentemente, a etnografia de Londoño Sulkin gira, na sua totalidade, em torno da descrição e da análise das teorias a partir das quais la Gente de Centro constrói suas avaliações e julgamentos morais sobre si mesma e sobre os outros - retratos morais, como os chama o autor. É esse recorte etnográfico sua principal contribuição e originalidade. O resultado é uma rica etnografia, prenhe de informações interessantes e considerações inteligentes, que instiga a refletir, a partir da óptica proposta, sobre a produção recente no campo da etnologia indígena amazônica.

Ao longo dos cinco capítulos de que consta o livro, o autor aborda diversos aspectos relacionados com o assunto central da moralidade, sendo a corporalidade o eixo que perpassa e aglutina a maior parte deles. $O$ livro mostra como a dimensão moral do self entre la gente de Centro se constitui através do acúmulo no corpo de discursos e de determinadas substâncias: tabaco, coca, pimenta, assim como os alimentos, são suas principais fontes. Essa característica, a construção moral da pessoa através da in-corporação de discursos e de substâncias, tem várias implicações. Em primeiro lugar, envolve um entendimento do self como processual, extrínseco e material. A concepção processual da pessoa é um tema abundantemente tratado na etnologia amazônica a partir do trabalho clássico de Seeger, Da Matta e Viveiros de Castro sobre construção social da pessoa: o corpo se torna objeto de manipulação de forma a modelar a pessoa visando o desenvolvimento das qualidades (morais no caso da etnografia de Londoño Sulkin) socialmente valorizadas. $O$ aspecto extrínseco do self, no que se refere à moralidade, constitui um dos temas a que o autor presta mais atenção. Em relação a esse ponto, ele argumenta que a pessoa não pode ser definida a partir da noção de unidade, em termos de intencionalidade e agência, mas se trata, antes, de "se/ves múltiplos que podem escolher ficar no interior da pessoa ou não se fixar nela" (:33). Porém, não se limita a isso. O self não apenas tem uma natureza divisível, fragmentada e externalizável, mas é também produto das ações dos outros. Um dos casos que ilustram esse aspecto é o de um jovem que atribuía seu comportamento reprovável ao fato de seu pai ter consumido cachaça e maconha quando novo. Ainda, a dimensão coletiva da moralidade de cada pessoa se evidencia em outras situações. Se alguém tem um comportamento moralmente reprovável, as outras pessoas não se limitam a criticá-lo, senão que podem tomar atitudes ou realizar ações que contribuam à correção do mesmo. Quando, por exemplo, uma 
mulher excedeu-se espalhando fofocas maldosas, seu vizinho matou um porquinho do mato e o deixou na frente da porta dela, alegando que era o porco quem a fazia se comportar assim, e que dessa forma ele teria removido as substâncias nocivas que estariam no interior do corpo dela. Agradecida, a mulher retribui com uma festa de bebida de mandioca (:118). Em relação a esse mesmo ponto, o penúltimo capítulo do livro está dedicado a mostrar como a produção dos corpos depende das interações rituais entre diferentes clãs. Em última instância, os membros de uma determinada comunidade fazem parte de um único corpo, de forma que sua manutenção e reprodução derivam do esforço coletivo. A esse respeito, um dos principais elementos desestabilizadores da coesão social é a displicência para ajudar os outros, o que, em termos de crítica moral, desencadeia acusações de preguiça e mesquinharia.

O carácter extrínseco do self e sua dimensão coletiva leva o autor, no segundo capítulo, a uma reflexão sobre a responsabilidade, tema que tem um lugar estratégico na economia geral da obra, já que um dos objetivos do livro é contribuir na produção antropológica, atualmente pujante, sobre a moralidade e, portanto, para uma reflexão sobre aspectos tais como estrutura, agência e liberdade (:4). De fato, nas considerações teóricas que se encontram no final do livro a questão é retomada. Um dos argumentos que o autor defende é que, conforme é mostrado na etnografia, as escolhas humanas não podem ser pensadas como epifenômenos das estruturas (:147). Se há uma noção descentrada e extrínseca do self que poderia aludir a uma falta de agência, ao mesmo tempo - o autor nos lembra para não incorrermos no erro - há uma retórica sobre a autonomia e a reflexividade $(: 62,63)$, aspectos estes que são identificados como a chave para o reconhecimento da agência dos atores sociais. Para além de voltar-se sobre questões sobejamente tratadas na teoria antropológica (as escolhas dos sujeitos não são epifenômenos das estruturas; as críticas à reificação do conceito de cultura e a dar uma imagem de homogeneidade de um determinado coletivo humano), resta, ainda, uma impressão de defasagem entre a etnografia e as conclusões teóricas. Sem discordar dessa afirmação genérica, cabe se perguntar até que ponto uma noção de agência que parece atrelada à noção de indivíduo (-valor, como especifica Dumont) - já que constituída a partir de ideias como liberdade individual, estratégias (que fazem referência a objetivos específicos da pessoa), autonomia e reflexividade como atributos inerentes ao sujeito - se adequa a uma noção de pessoa que, como o próprio autor demonstra etnograficamente de forma muito convincente, é extrínseca, relacional, histórica e processual. Frente à disjuntiva entre responsabilidade própria ou alheia em relação aos comportamentos de uma pessoa - que não parece ser apenas um problema para o antropólogo, mas também para la Gente de Centro -, a descrição etnográfica mostra que não há uma opinião única, mas, antes, uma constante negociação, sendo expostas, em cada caso, diversas concepções, nas quais estão envolvidas também diferenças decorrentes de mudanças históricas (:68). Levando essas questões em consideração, caberia, quiçá, ter derivado a noção de agência dos próprios dados etnográficos, como têm feito outros autores, em vez de pressupô-la a priori, ou seja, caracterizar, nesse caso, uma forma de agência que não é exclusiva dos humanos, e que, quando se refere a estes, resulta de uma noção de self autônomo e reflexivo, ao mesmo tempo em que extrínseco, material e coletivamente constituído.

Esta questão remete a outro conjunto de problemas que a etnografia de Londoño Sulkin levanta e que se refere à ambiguidade daquilo que é ou não é considerado moral, do ponto de vista de la Gente de Centro. Em relação ao conhecimento xamânico, tratado de forma mais detalhada no terceiro capítulo, se afirma que sua moralidade é relativa, dependendo da finalidade para a qual seja usado. A princípio, na medida em que se insere dentro do processo de 
construção de pessoas é moral, mas quando escorrega para o outro lado, quando tem como finalidade sua destruição, se trata então de bruxaria e, portanto, é imoral. Porém, para la Gente de Centro tanto a bruxaria quanto a raiva têm um apelo estético. Nessa linha de argumentação, a capacidade predatória, principalmente nos homens, não é apenas desejável, afirma o autor, mas também objeto de admiração, o que aparentemente é contraditório com o discurso sobre uma moralidade baseada no cuidado, no afeto, na calma. Obviamente, aqui nos encontramos ante uma questão recorrente nas etnografias: a construção social de pessoas necessariamente exige a destruição tanto de humanos quanto de não-humanos. Certos autores têm apontado o dilema moral, ou mal-estar conceitual, que isso representa, por exemplo, no caso da caça. Mas nem sempre a destruição do outro - humano ou não-humano - representa um dilema moral; antes desencadeia um perigo que deve ser neutralizado e, outrossim, exige a realização de operações rituais que permitam a apropriação e/ou domesticação da agência liberada com a morte. Se essa teleologia produtiva parece ser um aspecto que legitima moralmente a violência na Amazônia, não é o único. A vingança ou a violência defensiva podem ser objetivos julgados como legítimos pelos atores que os protagonizam. Não estamos aqui ante uma teoria do moral de caráter maniqueísta, que define de forma absoluta o que é certo do que não, pelo menos no que se refere ao exercício da violência e da agressão xamânica. Como aponta Londoño Sulkin, a moralidade a esse respeito depende de uma perspectiva pronominal. A avaliação de um determinado ato violento depende, em grande medida, do posicionamento do sujeito no conjunto das relações implicadas. $O$ apelo estético que a bruxaria e a raiva detêm, coloca a questão da sua condição no marco da moralidade, tal e como definida pelo autor. A ambiguidade e a aparente contradição assinalada parecem se engendrar da inexistência de uma teoria da moralidade totalizante e descolada das situações e posicionamentos concretos.

A ambiguidade relativa às emoções e à capacidade para a violência está conectada, por outro lado, com a lógica das substâncias. O tabaco é a substância por excelência, essencial na constituição da humanidade. É através do seu consumo regular que o parentesco é construído. Se ela é a fonte de emoções e pensamentos adequados (serenidade, compaixão pelos parentes, desejo de cuidar deles, etc.), é também a das capacidades predatórias e dos conhecimentos necessários para agir de forma violenta contra qualquer inimigo, capacidades e conhecimentos, estes, exclusivos dos homens (: 97,98). No caso das mulheres, a substância associada à raiva é a pimenta. Suas propriedades picantes, que podem produzir dano aos seres mal-intencionados, são fruto da raiva da mulher; porém, trata-se de uma raiva gerada a partir de pensamentos e emoções adequados e morais, e associada à capacidade produtiva.

Um dos desdobramentos dessa ambiguidade moral é sua intersecção com a teoria do perspectivismo e as nuances que o autor do livro aponta. Embora em termos fenomenológicos os mundos de humanos e não humanos sejam similares, la Gente de Centro considera que existem diferenças entre os seres no que respeita à sua moralidade, $\mathrm{e}$ diferenças que implicam uma hierarquia moral, sendo a moralidade dos animais e outros não-humanos intrinsecamente torcida e inferior. Esse é o ponto no qual se baseia o autor para afirmar que estaríamos ante uma cosmologia não totalmente perspectivista. Parece existir uma inflexão relativista no perspectivismo de la Gente de Centro: cada ser é "verdadeiramente humano" segundo seus próprios termos (: 57). Os animais, mesmo que se enxerguem a si próprios e a seus congêneres e parentes como humanos, não se comportam com estes como corresponde à gente verdadeira, ou seja, com amor, respeito e cuidado. Há uma hierarquia nas diferentes moralidades, que não são equivalentes, e sim, 
do ponto de vista dos humanos, hierarquicamente diferentes. Se os pensamentos/emoções de um não-humano em relação aos seus congêneres diferem daqueles próprios dos humanos verdadeiros (real people), então não pode se considerar que tem uma perspectiva propriamente humana (:57). Segundo essa lógica, é na moralidade onde radica o elemento particular e irredutível dos seres humanos. Por outro lado, parece estar pressuposto que pensamentos/ emoções e, portanto, moralidade, deveriam estar localizados naquilo que o perspectivismo postula como comum a todos os seres: a alma. Ora, a etnografia que nos ocupa demostra o enraizamento da moralidade no corpo, estando definida, constituída e moldada através da incorporação de substâncias. Mesmo que não o foquem do ponto de vista de moralidade, outras etnografias já têm insistido em que pensamentos e emoções no caso de vários povos amazônicos são mais uma questão corporal do que espiritual. Isso apontaria para o fato de que a moralidade (ou em termos mais genéricos emoções/pensamentos adequados e produtores de comportamentos apropriados) não é uma qualidade da "alma" e sim do "corpo", o que, no final das contas é mais um efeito do reembaralhamento de predicados nas séries paradigmáticas de "Natureza" e "Cultura" a que Eduardo Viveiros de Castro faz referência no seu artigo sobre o perspectivismo. As moralidades são tão específicas quanto os corpos onde se constituem, permeando, portanto, pontos de vista diferentes.

Essa reflexão nos leva, finalmente, a outra problemática apontada também por Carlos Londoño Sulkin: a da possibilidade de transitar entre pontos de vista diferentes - ou entre corpos diferentes. Dado que a moralidade radica no corpo, isso implicaria também transitar entre moralidades diferentes. Lembremos que para la Gente de Centro os seres humanos verdadeiros têm uma moralidade específica e superior em relação a outros seres. Numa ontologia transformacional e perspectivista, onde a potencialidade predatória é visada, são desejadas algumas capacidades dos grandes predadores, mas não assim seus afetos, hábitos e perspectivas (:57) (morais, poderíamos dizer). Esse apontamento levanta a questão de que os processos de transformação podem ter seus limites precisamente na pertinência da transitividade moral. O risco de assumir a perspectiva do outro, seja voluntária (quando o xamã se transforma em animal) ou involuntariamente (quando alguém é capturado por um não-humano e adoece, por exemplo) é, precisamente, não se comportar mais conforme os princípios morais dos seus semelhantes, deixar de se comportar como um parente. Se a moralidade está no corpo, então se transformar corporalmente envolve uma transformação moral não necessariamente visada. De fato, raramente as transformações voluntárias na Amazônia são totais; trata-se, no geral, de transformações controladas, parciais ou reversíveis. Se os corpos e seus processos constituem, enquanto núcleos simbólicos constantes, forças centrípetas que limitam, embora não anulem, o efeito da différance (:158) em termos de devir histórico e social, poderíamos ver na moralidade - tal e como definida e descrita pelo autor - o limite do permanente devir ontológico - se transformar em não-humano, “virar branco"... -que parece caracterizar o pensamento de muitos coletivos ameríndios.

Recebido em: 20/02/2014

Aprovado em: 29/04/2014
Laura Pérez Gil é doutora em Antropologia Social pela Universidade Federal de Santa Catarina (UFSC) e Professora Adjunta da Universidade Federal do Paraná (UFPR). 